\title{
Una nueva especie de Scutellaria (Labiatae) de Hidalgo, México
}

\author{
Patricia Hiriart Valencia ${ }^{1}$
}

\begin{abstract}
RESUMEN. Se describe una nueva especie de Scutellaria (S. molanguitensis), sección Resinosae, de la barranca de Tolantongo, Hidalgo, México.
\end{abstract}

Abstract. A new species of Scutellaria (S. molanguitensis), section Resinosae, from the barranca de Tolantongo, Hidalgo, México, is described.

Scutellaria molanguitensis Hiriart sp. n. (figs. 1 y 2).

Suffrutex rhizomatibus filiformibus ramosis; folia ovata 5-9 $\mathrm{mm}$ longa. Flores rubri in axillis foliorum superiorum dispositi; corolla labio supero trilobato, lobo medio profunde emarginato; labium inferius trilobatum, glandulis niveis versus basim obtectum. Nuculae nigrae tuberculatae.

TIPO: MÉXICO: Hidalgo; Municipio de Cardonal, barranca de Tolantongo (alt. 2100 m), $3 \mathrm{~km}$ al $\mathrm{N}$ de Molanguito, ladera caliza con matorral esclerófilo, 23 IX 1983, P. Hiriart, T.P. Ramamoorthy y J.L. Villaseñor 189 (HOLOTIPO: MEXU: isotipos para ser distribuidos).

PARATIPOS: México: Hidalgo; Municipio de Cardonal, barranca de Tolantongo, $3 \mathrm{~km}$ al $\mathrm{N}$ de Molanguito, 30 IV 1978, P. Hiriart 91 (MEXU), misma localidad, 5 VIII 1982, F. González Medrano y P. Hiriart 12780 (MEXU).

Sufrútice de 10 a $15 \mathrm{~cm}$ de altura con rizomas filiformes ramificados; ramas pardas obscuras, cubiertas por tricomas unicelulares cónicos y glándulas, con numerosas cicatrices foliares. Hojas con pecíolo de $1 \mathrm{~mm}$ de largo; lámina de 5-9 $\mathrm{mm}$ de largo y de 2-6 mm de ancho, ovada a elíptica, ápice agudo, base redondeada, margen entero, revoluto y con cierta coloración rojiza hacia el ápice, las dos caras con la superficie glandulosa, con una nervadura principal y dos a cuatro nervaduras secundarias poco notables. Flores solitarias en las axilas de las hojas superiores, sustentadas por dos bracteolas lineares de $1 \mathrm{~mm}$ de largo. Pedúnculos de $2 \mathrm{~mm}$ de largo con el indumento igual al del tallo; cáliz de cerca de $4 \mathrm{~mm}$ de largo y casi de $3 \mathrm{~mm}$ de ancho, bilabiado, verde, con el margen de los labios rojo, cubierto por pequeñas glándulas sésiles y algunos tricomas glandulares esparcidos, labios enteros, el superior redondo, portando el escutelo (más ancho

${ }^{1}$ Departamento de Botánica, Instituto de Biología, Universidad Nacional Autónoma de México, Apdo. Postal 70-233, 04510 México, D.F. 

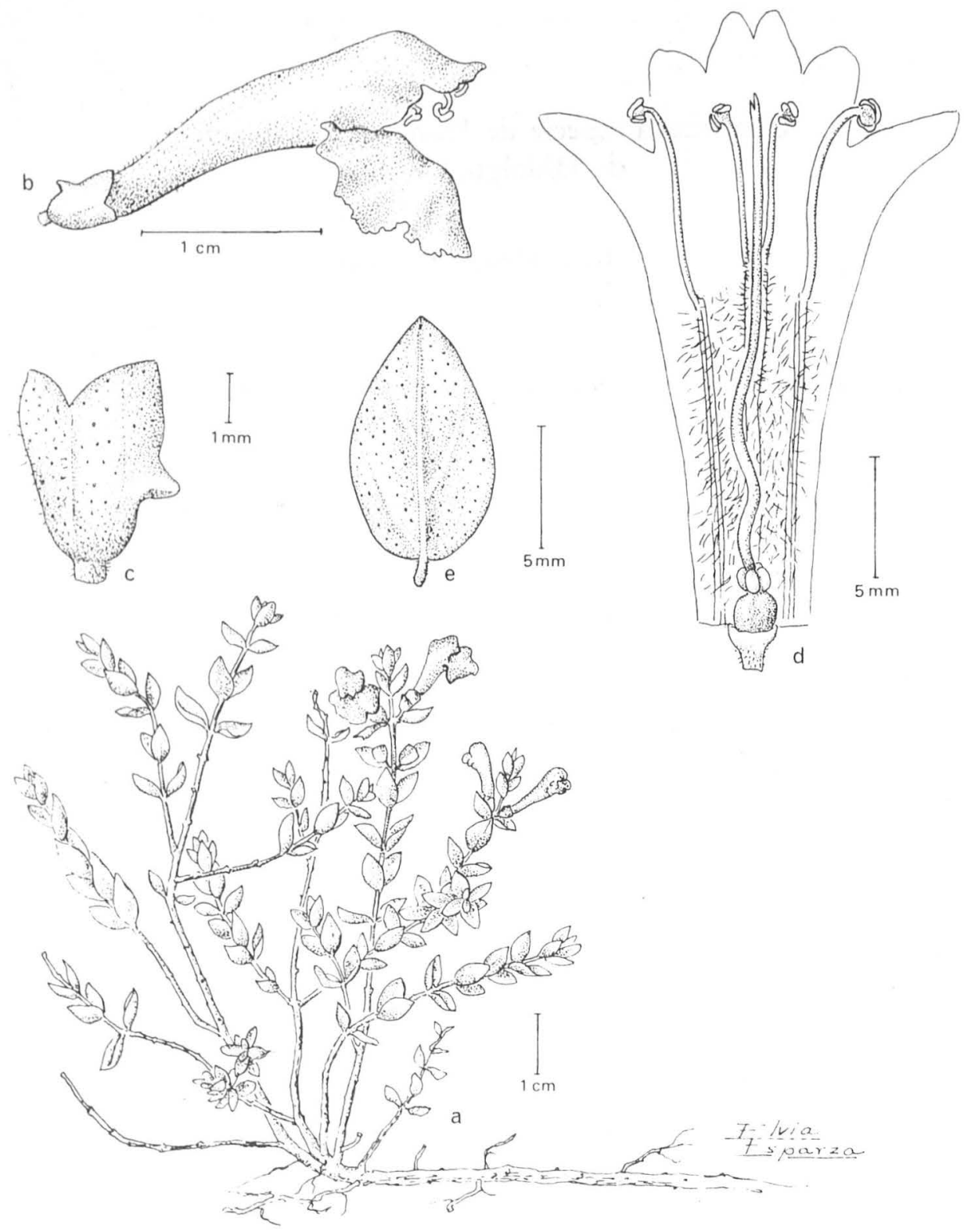

Fig. 1. Scutellaria molanguitensis. a. Planta con flores; b. Flor; c. Cáliz; d. Interior de la corola mostrando los estambres y el gineceo; e. hoja. 


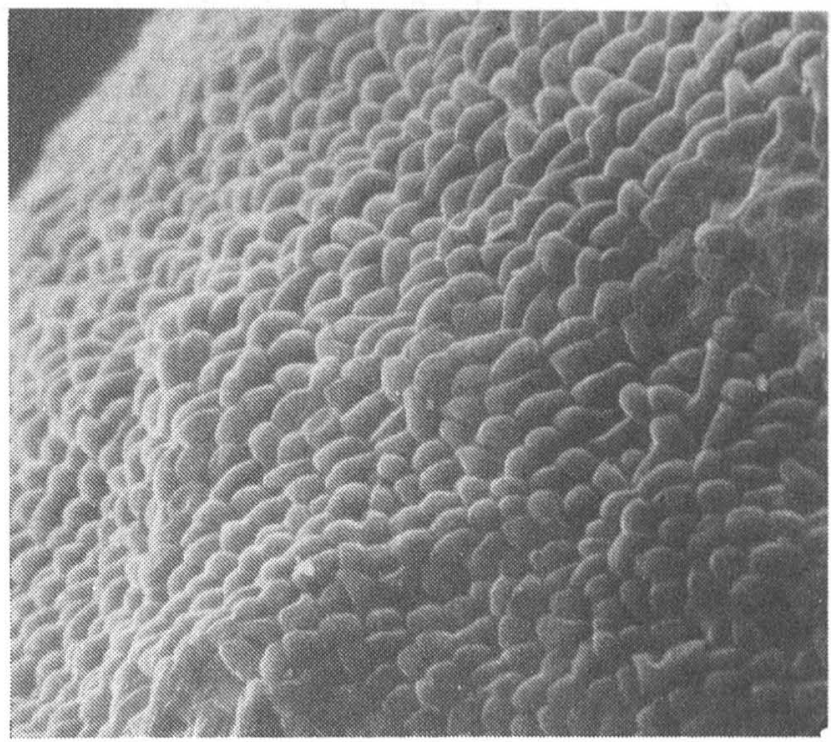

Fig. 2. Superficie tuberculada del fruto de Scutellaria molanguitensis (400X) observado en el microscopio electrónico de barrido.

que alto) hacia la base, labio inferior redondo. Corola roja de $20-22 \mathrm{~mm}$ de largo; tubo de 10-12 mm de largo por $2 \mathrm{~mm}$ de ancho, superficie externa cubierta por tricomas multicelulares y tricomas glandulares, superficie interna por debajo de la porción media densamente vellosa; labio superior de $5 \mathrm{~mm}$ de largo, trilobulado, lóbulos laterales redondos, lóbulo medio profundamente emarginado; labio inferior de $8-12 \mathrm{~mm}$ de largo, trilobulado, con lóbulos laterales más cortos, redondos, lóbulo medio prominente, redondo, cubierto por glándulas pequeñas, blancas hacia la base. Estambres 4, insertos justo por debajo de la garganta, inclusos, didínamos, filamentos vellosos hacia la base, los mayores de 5-7 mm de largo, los menores de 3-4 $\mathrm{mm}$ de largo; anteras con dos tecas divergentes, las anteras de los estambres inferiores con una de las tecas reducida; estilo de 15-18 mm de largo, dividido en dos brazos desiguales. Nuececillas negras, de $2 \mathrm{~mm}$ por $1 \mathrm{~mm}$, tuberculadas.

Esta especie vive en el matorral esclerófilo sobre las rocas, en terrenos calizos de fuerte pendiente y con orientación norte.

Siguiendo la clave de Epling (1942, p. 7), esta especie quedaría comprendida en Scutellaria sección Spinosae. Epling segrega esta sección de otras de flores azules basándose en el color rojo de las flores; sin embargo, el carácter más importante para separar la sección parece ser la presencia de ramas rígidas subespinosas. Aunque S. molanguitensis posee flores rojas, no presenta ramas subespinosas. Por su forma de vida, sus hojas pequeñas y enteras, las flores axilares en la porción superior media de la planta, el escutelo más ancho que alto, el tubo de la corola piloso por debajo del punto de unión de los estambres y el fruto subgloboso, esta especie queda mejor ubicada dentro de la sección 
Resinosae, aunque sus flores no sean azules. S. molanguitensis puede ser reconocida rápidamente por sus flores rojas y su indumento hispídulo corto.

S. molanguitensis se conoce hasta ahora solamente de la barranca de Tolantongo, Hidalgo. Se suma al grupo de Labiatae endémicas de esta zona, como Salvia bidalguensis Miranda y Neoeplingia leucophylloides Ramamoorthy, Hiriart \& Medrano.

El epíteto específico molanguitensis alude al nombre de la localidad (Molanguito) donde crece esta planta.

Agradecimientos. Agradezco al Dr. T.P. Ramamoorthy su revisión crítica del manuscrito, al Dr. Fernando Chiang la traducción al latín, al M. en C. Francisco González Medrano la revisión del texto, a Yolanda Ornelas el haber tomado la fotografía del fruto. La ilustración es obra de Elvia Esparza, del Instituto de Biología, UNAM.

\section{LITERATURA CITADA}

Epling, C. 1942. The American species of Scutellaria. Univ. Calif. Publ. Bot. 20 (1):1-146. 